Chia-Huei WU ${ }^{1}$, Sang-Bing TSAI ${ }^{2 *}$, Wei LIU ${ }^{3 *}$, Xue-Feng SHAO ${ }^{4}$, Rui SUN ${ }^{5}$ and Maria WACŁAWEK ${ }^{6}$

\title{
ECO-TECHNOLOGY AND ECO-INNOVATION FOR GREEN SUSTAINABLE GROWTH
}

\section{This SI commemorates Professor Witold Wacławek}

The world has developed to the point where productive activities are no longer only about profit and efficiency. With the rapid development of eco-technology across the world, the demand for eco-technology is growing rapidly and the question of how to protect the environment in production activities has been a popular topic for researchers in various countries. It was an inspiration for Professor Witold Wacławek (1938-2020) to found in 1992 a Central European Conference ECOpole and in 1994 the journal Ecological Chemistry and Engineering [1]. This Special Issue is dedicated to him.

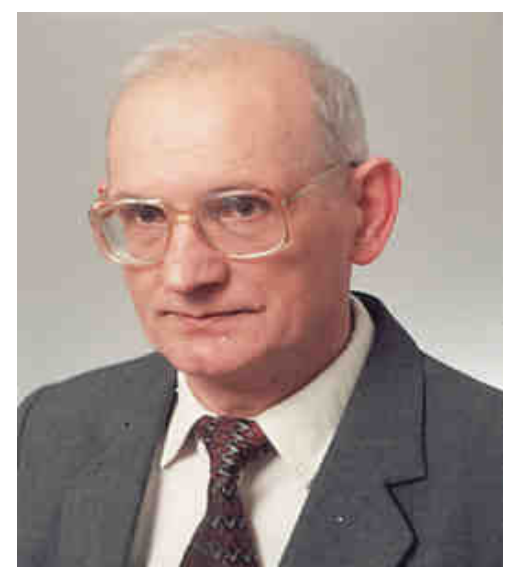

\footnotetext{
${ }^{1}$ Department of Hotel Management and Culinary Creativity, Minghsin University of Science and Technology, Hsinchu 304, Taiwan

${ }^{2}$ Regional Green Economy Development Research Center, School of Business, WUYI University, Nanping 354399, China

${ }^{3}$ Business School, Qingdao University, Qingdao 266061, China

${ }^{4}$ Newcastle Business School, The University of Newcastle, Hunter St \& Auckland St, Newcastle 2300, Australia

${ }^{5}$ Business School, Huaqiao University, Quanzhou 362021, China

${ }^{6}$ University of Opole, ul. kard. B. Kominka 6, 45-032 Opole, Poland

*Corresponding author: sangbing@hotmail.com (S.T.); dqytliu@ gmail.com (W.L.)
} 
In order to understand the impact of human activity on nature, scholars have contributed 10 research articles, presented in this special issue of the Ecological Chemistry and Engineering $S$ (ECES). Specifically, Wacławek [2] provided an overview of the existing computational methods for describing the oxidative degradation of pollutants in terms of advanced oxidation processes (AOP, i.e., techniques utilizing $\mathrm{OH}$ radical for degradation of pollutants). The regioselectivity of the Acid Blue 129 compound is discussed as an example, and it was concluded that with the development of the information technology age, quantum chemical calculations (QCC) will not only become more accurate and accessible, but will also replace most of the experimental studies related to pollutant remediation in the future. The identification of substances cannot only be carried out in the laboratory, but also it is vital to carry out chemical analyses of different substances where the analytes are present. However, this analysis needs to be supported by the appropriate mobile device. In this context, Witkiewicz and Wardencki [3] started the presentation by describing the progress of research in combining mass and ion mobility spectrometry (MS, IMS) with miniature gas chromatography (GC). They explained that both systems can be used not only for the analysis of typical chemicals present in different environmental compartments (air, water and soil samples), but also for the analysis of explosives, drugs and chemical warfare agents when fast results are needed. The application of small GC-MS and GC-IMS units are presented and of particular interest are their applications in space exploration on the International Space Station. The authors also suggested that the miniaturisation of conventional gas chromatographs, mass spectrometers and ion mobility spectrometers are possible using innovative technologies (MEMS, NEMS), new methods (microfluidics) and presenting their advantages and disadvantages.

In order to maintain ecological sustainability in the face of economic prosperity, we do not only have to study pollutants, but also how to develop environmentally friendly materials and reap the benefits. In the context of the increasing use of construction adhesives, Liu et al. [4] investigated the potential of nano-rubber (VP-501: diameter of $\sim 70 \mathrm{~nm}$ ) to improve the static tensile properties, fracture toughness and dynamic mechanical properties of epoxy resins. In addition, they also investigated the effect of toughening agent content on its thermal stability and glass transition temperature, further exploring the mechanism of toughening and heat resistance of modified epoxy resins, making a contribution to the future use of environmentally friendly building structure materials. Shuai et al. [5] have further studied green low-carbon cable materials based on rough set theory, using energy-saving equal channel angular pressing (ECAP) technology instead of the traditional heat treatment process to convert simple heat transfer into thermo-mechanical energy, to achieve good strength and conductivity matching of cable aluminum alloy materials. The results can be used in the cable industry for technological upgrading and low carbon production, significantly reducing energy consumption heat treatment time and efficiently obtaining high quality products. As for exploring the benefits of energy saving and emission reduction, Zhong et al. [6] established an evaluation system with three rule levels: social, economic and environmental, and used rough set theory to determine the relative importance/magnitude of each factor in the context of energy saving and emission reduction of construction waste slurry treatment in Guangdong Province, China. Based on the recommendations of the carbon emission calculation guidelines, relevant data were selected to evaluate the energy saving and emission reduction benefits of the new green construction technology for grouted piles in a highway project in Guangdong Province. This study will not only evaluate the benefits of energy saving and emission 
reduction, but will also serve as a reference for the evaluation of energy saving and emission reduction in the construction industry in other countries.

Building a green and sustainable world does not stop at the laboratory or the selection of materials, as the recognition of the concept of sustainability by human beings and its application in practice is more important. $\mathrm{Wu}$ [7] believes that rooting the idea of green is the first step to ensuring the sustainability of the planet. Using the Decision Making Trial and Evaluation Laboratory (DEMATEL) as a tool, his study explores the criteria for evaluating green universities and the causal relationships between the criteria, and makes recommendations for green performance management at case universities that can effectively help schools develop environmental policies.

With the progress of urban construction and urban greening projects, Zhao and Liu [8] used Linear Spectral Mixing Model (LSMM) and variational domain raster analysis to analyse the spatial and temporal variation patterns of vegetation composition in urban Xi'an and its influencing factors based on a linear spectral mixture model. This study not only provides rapid information on the dynamic changes of urban vegetation, but also offers suggestions and data support for urban ecological and environmental protection planning and for the construction of a green city. Chen et al. [9] examine the sustainable development of air traffic control (ATC) units. They studied the feedback relationships among control, communication, navigation and information subsystems, based on the system prototype "growth and underinvestment" and the feedback relationship among security capacity, safety and development, starting from the leverage point of the conflict between supply and demand using Tianjin ATC Branch as the case. In this study, the causal relationship between dynamic elements such as control, communication, safety and development, and meteorological and information subsystems is investigated. On this basis, a system dynamics model for the sustainable and safe development of ATC crews is developed to explain the complex interactive feedback mechanisms and dynamic mechanisms among the factors of the air traffic control system, and policy recommendations. The economic aspects of sustainable development have been studied by Han et al. [10]. As the uneven growth of foreign direct investment in China has significantly affected the coordinated development of China's regional economy, they use the New Political Economy theory and spillover effects as the basis for a comparative and statistical research method combining static and dynamic analysis, and an empirical research method combining with a normative study to analyse the spillover effects of FDI on China's sustainable development. This study is helpful in how to promote FDI in China and the development of our sustainable development strategy in the context of the global crisis and the difficult new situation that accompanies it.

In addition, $\mathrm{Wu}$ and Zhou [11] used OLS regression to analyse the mechanism of the influence of NFCs on the adoption of green control technologies by farmers, further validating the mediating role of information access. The results show that Need For Cognitive Closure (NFCC) has a direct influence on the adoption of green control technologies and that information acquisition has a mediating role. The results of this study have theoretical implications for expanding farmers' knowledge of green control technology behaviour and further enriching their cognitive research.

In summary, scholars in different countries and fields are working on ways to make science greener. In the field of eco-technology, environmental assessment or green agriculture, the topic of green environment and sustainable development will continue to be a major topic which will be worthy of future exploration. 


\section{References}

[1] Professor Witold Waclawek (1938-2020), founder and president of the Society of Ecological Chemistry and Engineering died. Ecol Chem Eng S. 2020;27(1):7-8.

[2] Wacławek S. Do we still need a laboratory to study advanced oxidation processes? A review of the modelling of radical reactions used for water treatment. Ecol Chem Eng S. 2021:28(1):11-28. DOI: 10.2478/eces-2021-0002.

[3] Witkiewicz Z, Wardencki W. Mobile gas chromatographs coupled with mass and ion mobility spectrometers and their applications. Ecol Chem Eng S. 2021:28(1):29-37. DOI: 10.2478/eces-2021-0003.

[4] Liu M, Zhang L, Lee C. New epoxy with self-repairing properties of environmental-friendly building structure adhesives. Ecol Chem Eng S. 2021:28(1):39-48. DOI: 10.2478/eces-2021-0004.

[5] Shuai G, Li Z, Zhang D, Elhefnawey M, Li L. On rough set theory on achieving high quality cable material production by green low carbon technology. Ecol Chem Eng S. 2021:28(1):49-59. DOI: 10.2478/eces-2021-0005.

[6] Zhong Z, Zhang X, Yang X. Benefit evaluation of energy-saving and emission reduction in construction industry based on rough set theory. Ecol Chem Eng S. 2021:28(1):61-73. DOI: 10.2478/eces-2021-0006.

[7] Wu C-H. An empirical study on discussion and evaluation of green university. Ecol Chem Eng S. 2021:28(1):75-85. DOI: 10.2478/eces-2021-0007.

[8] Zhao X, Liu J. Quantifying urban vegetation coverage change with a linear spectral mixing model: A case study in Xi'an, China. Ecol Chem Eng S. 2021:28(1):87-100. DOI: 10.2478/eces-2021-0008.

[9] Chen F, Chen X, Zhang X. An empirical study on system dynamics model for sustainable development of air traffic control units. Ecol Chem Eng S. 2021:28(1):101-16. DOI: 10.2478/eces-2021-0009.

[10] Han J, Chen Y, Sun H. Foreign direct investment spillover effect on China's sustainable development. Ecol Chem Eng S. 2021:28(1):117-27. DOI: 10.2478/eces-2021-0010.

[11] Wu Q, Zhou J. Need for cognitive closure, information acquisition and adoption of green prevention and control technology. Ecol Chem Eng S. 2021:28(1):129-43. DOI: 10.2478/eces-2021-0011. 